Available online at

ScienceDirect

www.sciencedirect.com
Elsevier Masson France

EM|consulte

www.em-consulte.com/en
Clinics and Research in $\mathrm{H}_{\text {epatolog }}$ and $\mathbf{G}_{\text {astroenterology }}$

काष

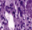

\title{
Effects of preventive versus "on-demand" nutritional support on paid labour productivity, physical exercise and performance status during PEG-interferon-containing treatment for hepatitis $C^{\text {is }}$
}

\author{
Ellen J. Huisman ${ }^{\mathrm{a}, 1}$, Suzanne van Meer ${ }^{\mathrm{a}, 1}$, Bart van Hoek ${ }^{\mathrm{b}}$, \\ Hanneke van Soest ${ }^{c}$, Karin M.J. van Nieuwkerk ${ }^{d}$, \\ Joop E. Arends ${ }^{e}$, Peter D. Siersema ${ }^{a}$, Karel J. van Erpecum ${ }^{a, *}$
}

\footnotetext{
a Department of Gastroenterology and Hepatology, University Medical Center, Utrecht, The Netherlands

b Department of Gastroenterology and Hepatology, University Medical Center, Leiden, The Netherlands

c Department of Gastroenterology and Hepatology, Medical Center Haaglanden, The Hague, The Netherlands

d Department of Gastroenterology and Hepatology, VU Medical Center, Amsterdam, The Netherlands

e Department of Internal Medicine and Infectious Diseases, University Medical Center, Utrecht, The Netherlands
}

Available online 15 July 2015

\begin{abstract}
Summary
Background and objective: Deterioration of nutritional status during PEG-interferon containing therapy for chronic hepatitis $\mathrm{C}$ can be ameliorated by preventive nutritional support. We aimed to explore whether such support also affects paid labour productivity, physical exercise and performance status.
\end{abstract}

\footnotetext{
This study was registered at ClinicalTrials.gov (identifier NCT00841243).

* Corresponding author. Department of Gastroenterology and Hepatology, University Medical Center Utrecht, PO BOX 85500,3508 GA Utrecht, The Netherlands. Tel.: +318 87557004 .

E-mail address: k.j.vanerpecum@umcutrecht.nl (K.J. van Erpecum).

1 These authors contributed equally to this manuscript and share first authorship.

Abbreviations: CHC, Chronic hepatitis C; PEG, Pegylated; SVR, Sustained virological response; RCT, Randomized controlled trial; HCV, Hepatitis $C$ virus; KPS, Karnofsky performance status.
} 
Methods: In this prospective randomized controlled trial (J Hepatol 2012;57:1069-75), 53 patients with chronic hepatitis $C$ had been allocated to "on demand" support $(n=26$ : nutritional intervention if weight loss $>5 \%)$ or preventive support $(n=27$ : regular dietary advice plus energy- and protein-rich evening snack) during PEG-interferon-containing therapy. Paid labour productivity, physical exercise and performance status were evaluated at baseline, after 24 and (if applicable) after 48 weeks of treatment.

Results: At baseline, $46 \%$ of patients performed paid labour and $62 \%$ performed some kind of physical exercise. Furthermore, most patients were able to carry out normal activity with only minor symptoms of disease (mean Karnofsky performance score: 94). Decreases of paid labour productivity $(-21 \%$ vs. $-70 \%, P=0.003)$, physical exercise activity $(-43 \%$ vs. $-87 \%, P=0.005)$ and Karnofsky performance scores $(-12 \%$ vs. $-24 \%, P<0.001)$ were less in the preventive than in "on demand" group after 24 weeks of treatment. Effects of preventive nutritional support were even more pronounced after 48 weeks.

Conclusions: Preventive nutritional support markedly ameliorates decreases of paid labour productivity, physical exercise and performance status during PEG-interferon-containing treatment for chronic hepatitis C.

(c) 2015 Elsevier Masson SAS. All rights reserved.

\section{Introduction}

Chronic hepatitis $\mathrm{C}(\mathrm{CHC})$ is a leading cause of liver cirrhosis worldwide. Antiviral therapy for CHC has changed strongly over the past few decades and is nowadays highly effective. Until 2012, combined pegylated (PEG)-interferon plus ribavirin was the standard of care for $\mathrm{CHC}$ and resulted in a sustained virological response (SVR) in $40-90 \%$ of treatmentnaïve patients [1-4]. Nevertheless, interferon containing antiviral therapy is associated with significant side effects, which may affect paid labour productivity, physical exercise activity and performance status.

Significant weight loss during interferon-containing antiviral therapy often occurs because of decreased appetite due to fatigue, fever, nausea, depression or taste changes during antiviral treatment [5]. Furthermore, interferon- $\alpha$-based therapy delays gastric emptying, which could lead to upper abdominal discomfort and less appetite [6]. Average weight loss during treatment is reported to be approximately $7 \%$ of basal weight $[5,7,8]$. Weight loss may be even more pronounced with triple therapy containing protease inhibitors [9]. Severe weight loss during antiviral therapy is accompanied by a catabolic state and protein-energy malnutrition, which is also a frequent phenomenon in advanced hepatic disease [10]. A late-evening protein-rich nutritional supplement induces an anabolic state in patients with advanced liver disease [11]. In a recently published randomized controlled trial (RCT) [7], we found that preventive nutritional advice plus an energyand protein-rich evening snack before bedtime also prevents deterioration of nutritional status of patients during PEG-interferon-containing antiviral treatment for $\mathrm{CHC}$, with improved digestive symptoms and quality of life. Of note, such nutritional support also prevents catabolic state, as indicated by preserved handgrip strength according to Jamar [12-14], pinch grip strength and other parameters of nutritional state [7].
In previous studies, presence of $\mathrm{CHC}$ was associated with less work productivity and more absenteeism [15]. These findings were even more pronounced during PEG-interferoncontaining therapy [16-19].

In the current study, we examine the effects of preventive versus "on-demand" nutritional advice plus supplementation on paid labour productivity, physical exercise and performance status during PEG-interferoncontaining treatment for $\mathrm{CHC}$.

\section{Patients and methods}

\section{Patient and clinical characteristics}

In a previously published RCT performed in the period 2008-2010, we evaluated potential beneficial effects of preventive nutritional support during PEG-interferoncontaining antiviral treatment for $\mathrm{CHC}$ on nutritional state and quality of life [7]. Nevertheless, no data on paid labour productivity, physical exercise or performance status have been included in this previous publication. We therefore analyzed data on effects of preventive nutritional support on paid labour activity, physical exercise and performance status. These data had been prospectively collected and were all available in the database of this RCT. In total, 53 patients tested positive for serum hepatitis $\mathrm{C}$ virus (HCV)antibodies and HCV RNA during at least 6 months and with an indication for antiviral treatment [20-22] were randomized for the "on demand" group $(n=27)$ or the preventive group $(n=26)$. Both groups received PEG-interferon alfa2b $1.5 \mu \mathrm{g} / \mathrm{kg} /$ week subcutaneously and oral ribavirin for 24 or 48 weeks depending on genotype and viral load. Ribavirin dose was $800,1000,1200$, and $1400 \mathrm{mg} /$ day for body weight $<65 \mathrm{~kg}, 65-75 \mathrm{~kg}, 76-105 \mathrm{~kg}$, and $>105 \mathrm{~kg}$, respectively. Duration of antiviral therapy was $29 \pm 14$ weeks in the "on demand" and $32 \pm 12$ weeks in the preventive group $(P=0.268)$. Average PEG-interferon $\alpha-2 b$ dosage $(1.55 \pm 0.23$ 
and $1.41 \pm 0.3 \mu \mathrm{g} / \mathrm{kg} /$ week) and ribavirin dosage $(13.9 \pm 1.6$ and $14.5 \pm 2.1 \mathrm{mg} / \mathrm{kg} /$ day) did not differ between both groups [7]. In the preventive group, patients received dietary advice from a specialized nutritionist during their regular visits as well as an energy- and protein-rich evening snack to be taken daily before bedtime. Dietary advice included frequent energy and protein enriched meals with a high ratio of protein versus carbohydrates during the day. The prescribed Nutridrink protein ${ }^{\circledR}$ (Nutricia, Zoetermeer, The Netherlands) contains $20 \mathrm{~g}$ protein, $300 \mathrm{kcal}$ and $25 \%$ of the advised daily amounts of all other essential nutrients. Only in case of significant (> $5 \%$ of baseline) weight loss, patients in the "on demand" group received dietary advice and supplementation. The study was conducted according to recommendations of Good Clinical Practice and the Declaration of Helsinki. Written informed consent was provided by all patients and the protocol was approved by the medical ethical committees of all participating centres. This study was registered at ClinicalTrials.gov (identifier NCT00841243).

\section{Paid labour productivity}

For the assessment of paid labour productivity, we asked the patients to provide us with their productivity status at baseline and at the endpoint of 24 weeks and, if applicable, 48 weeks of treatment. Paid labour productivity was defined as paid full time or part time white collar (physically inactive) labour, blue collar (physically active) labour or none. Loss of paid labour productivity was based on percentage of baseline productivity at 24 weeks and, if applicable, 48 weeks of treatment, in only those patients who had any kind of paid labour productivity at baseline and separately for the total group (those with as well as those without paid labour activity at baseline). In addition, unpaid household activities were assessed in all patients without paid labour productivity at baseline.

\section{Physical exercise}

For the assessment of physical exercise (outside paid labour working hours), we asked the patients to provide us with their weekly physical exercise activity at baseline and at the endpoint of 24 weeks and, if applicable, 48 weeks of treatment. Patients were divided into the following subgroups according to their physical exercise activity per week:

- none;

- 60 to 150 minutes of low intensity exercise;

- > 150 minutes of low intensity exercise;

- 60 to 150 minutes of high intensity exercise;

- $>150$ minutes of high intensity exercise.

Low intensity exercise was defined as walking and leisure cycling. High intensity exercise was defined as strength training, running and intense cycling. Loss of physical exercise was defined as percentage of baseline physical exercise activity at 24 weeks and, if applicable, 48 weeks of treatment, in only those patients with any level of physical activity at baseline and separately for the total group.

\section{Performance status}

The Karnofsky performance status (KPS) scale, which ranges from $0-100$, was used to evaluate performance status outcomes of patients at baseline, at 24 weeks and, if applicable, 48 weeks of antiviral treatment [23].

\section{Statistical analysis}

Continuous data are given as means and standard deviations (SD) or, in case of a non-parametric distribution, as medians and ranges, and discrete variables as absolute and relative frequencies. Differences between the "on demand" and preventive groups were tested for statistical significance by independent $t$-test, Mann-Whitney $U$-test or Pearson $\mathrm{Chi}^{2}$ test, as appropriate. Pair-samples $t$-test was used to compare differences between time points in the same group. A two-sided $P$-value $<0.05$ was considered statistically significant. Statistical analysis was performed using SPSS version 21.0 for Windows.

\section{Results}

\section{Patient and clinical characteristics}

Baseline characteristics of all 53 patients who were randomized for the "on demand" group $(n=27)$ or the preventive group ( $n=26)$, and separately for those who reached the primary endpoint of 24 weeks of antiviral treatment $(n=22$ in both groups) are given in Table 1 . Mean age was 49 years and majority of patients was male (72\%). Furthermore, $87 \%$ of patients were treatment-naïve and half of patients (53\%) had only mild liver disease (F0-2). In the patients who were treated for at least 24 weeks ( $n=22$ in both groups), there were no significant differences in baseline host or viral characteristics between both treatment arms, except a higher proportion of co-morbidity in the preventive group (Table 1).

\section{Effects of preventive nutritional support during antiviral treatment on paid labour productivity}

At baseline, paid labour was performed by 24 of the 53 patients (46\%): $15 \%$ performed full time white collar labour, $19 \%$ full time blue collar labour, $6 \%$ part time white collar labour and 6\% part time blue collar labour. There were no significant differences in paid labour productivity between the "on demand"' and preventive groups (Table 1). Of the patients without paid labour productivity at baseline $(n=29), 13$ patients $(45 \%)$ performed unpaid household activities.

Data on paid labour productivity during antiviral therapy are given in Fig. $1 \mathrm{~A}$ and $\mathrm{B}$. After 24 weeks of treatment, paid labour productivity decreased in both groups, but loss of paid labour productivity was significantly larger in the "on demand" group $(-70 \%)$ than in the preventive group $(-21 \%)$ $(P=0.003)$ (Fig. $1 \mathrm{~A}$ and $\mathrm{B})$, based on only those patients with any paid labour at baseline $(n=22)$. After 48 weeks of treatment this difference was even greater: $-89 \%$ in the "on demand" 'group vs. $-17 \%$ in the preventive group $(P=0.023)$ (Fig. $1 \mathrm{~A}$ and $1 \mathrm{~B})$. When the total group $(n=44)$ was taken 
Table 1 Baseline characteristics of 53 chronic hepatitis C patients and separately for the patients with "on demand" nutritional support $(n=22)$ or preventive nutritional support $(n=22)$ who continued antiviral therapy during at least 24 weeks.

\begin{tabular}{|c|c|c|c|c|}
\hline & $\begin{array}{l}\text { All patients } \\
(n=53)\end{array}$ & $\begin{array}{l}\text { "On demand" group } \\
(n=22)\end{array}$ & $\begin{array}{l}\text { Preventive group } \\
(n=22)\end{array}$ & $P$-value \\
\hline Age (years), mean (SD) & $49 \pm 11$ & $51 \pm 9$ & $45 \pm 11$ & 0.063 \\
\hline Male sex, $n(\%)$ & $38(72)$ & $15(68)$ & $17(77)$ & 0.498 \\
\hline Weight (kg), median (range) & $80(46-105)$ & $78(69-83)$ & $79(69-81)$ & 0.841 \\
\hline BMI $\left(\mathrm{kg} / \mathrm{m}^{2}\right)$, mean $(\mathrm{SD})$ & $25.9 \pm 4.0$ & $25.5 \pm 4.3$ & $24.9 \pm 3.4$ & 0.751 \\
\hline HCV genotype, $n(\%)$ & & & & 0.365 \\
\hline 1 or 4 & $30(57)$ & $10(45)$ & $13(59)$ & \\
\hline Other & $23(43)$ & $12(55)$ & $9(41)$ & \\
\hline Nä̈ve, $n(\%)$ & $46(87)$ & $20(91)$ & $19(86)$ & 0.635 \\
\hline Liver disease, $n(\%)$ & & & & 0.761 \\
\hline F0-2 & $28(53)$ & $12(55)$ & $13(59)$ & \\
\hline $\mathrm{F} 3-4$ & $24(45)$ & $10(45)$ & $9(41)$ & \\
\hline Missing data & $1(2)$ & $0(0)$ & $0(0)$ & \\
\hline Co-morbidity, $n$ (\%) & $20(38)$ & $4(18)$ & $11(50)$ & 0.026 \\
\hline Cause of disease, $n(\%)$ & & & & 0.082 \\
\hline IV drug use & $13(25)$ & $8(36)$ & $3(14)$ & \\
\hline Other & $40(75)$ & $14(64)$ & $19(86)$ & \\
\hline Baseline viremia, $n(\%)$ & & & & 0.353 \\
\hline Low viral load $(<400,000 \mathrm{lU} / \mathrm{mL})$ & $25(47)$ & $12(55)$ & $15(68)$ & \\
\hline High viral load (> 400,000 IU/mL) & $28(53)$ & $10(45)$ & $7(32)$ & \\
\hline \multicolumn{5}{|l|}{ Routine blood tests, median (range) } \\
\hline AST (U/L) & $54(13-241)$ & $54(48-105)$ & $70(52-95)$ & 0.808 \\
\hline ALT $(U / L)$ & $86(29-417)$ & $106(81-169)$ & $84(74-127)$ & 0.552 \\
\hline Alkaline phosphatase (U/L) & $81(25-156)$ & $86(73-94)$ & $77(68-97)$ & 0.974 \\
\hline Albumin $(\mathrm{g} / \mathrm{L})$ & $41.2(30.7-48.0)$ & $41.2(39.1-42.7)$ & $40.5(38.7-42.2)$ & 0.715 \\
\hline$\gamma \mathrm{GT}(\mathrm{U} / \mathrm{L})$ & $43(15-371)$ & $38(30-76)$ & $53(29-127)$ & 0.742 \\
\hline Bilirubin $(\mu \mathrm{mol} / \mathrm{L})$ & $16(4-29)$ & $14(13-19)$ & $16(13-21)$ & 0.783 \\
\hline INR & $1.02(0.95-1.48)$ & $1.02(1.01-1.08)$ & $1.04(1.02-1.17)$ & 0.359 \\
\hline PTT (s) & $13.7(9.9-17.9)$ & $13.7(12.7-14.1)$ & $13.7(12.5-14.6)$ & 0.977 \\
\hline Creatinine $(\mu \mathrm{mol} / \mathrm{L})$ & $75(41-106)$ & $72(65-76)$ & $75(62-84)$ & 0.172 \\
\hline Haemoglobin (mmol/L) & $9.1(7.4-10.6)$ & $8.9(8.5-9.4)$ & $9.3(9.0-9.8)$ & 0.307 \\
\hline $\mathrm{TSH}(\mathrm{mlU} / \mathrm{L})$ & $1.2(0.6-3.9)$ & $1.1(1.1-2.1)$ & $1.6(1.2-2.3)$ & 0.759 \\
\hline Thrombocytes $\left(\times 10^{9} / \mathrm{L}\right)$ & $200(43-371)$ & $206(179-236)$ & $212(170-257)$ & 0.867 \\
\hline Paid labour productivity, $n$ (\%) & & & & 0.579 \\
\hline None & $29(54)$ & $11(50)$ & $11(50)$ & \\
\hline Full time white collar & $8(15)$ & $3(14)$ & $4(18)$ & \\
\hline Full time blue collar & $10(19)$ & $6(27)$ & $4(18)$ & \\
\hline Part time white collar & $3(6)$ & $0(0)$ & $2(9)$ & \\
\hline Part time blue collar & $3(6)$ & $2(9)$ & $1(5)$ & \\
\hline Unpaid household activities ${ }^{a}, n(\%)$ & $n=29$ & $n=11$ & $n=11$ & 0.193 \\
\hline Yes & $13(45)$ & $6(55)$ & $3(27)$ & \\
\hline None & $16(55)$ & $5(45)$ & $8(73)$ & \\
\hline Physical exercise, $n$ (\%) & & & & 0.953 \\
\hline None & $20(38)$ & $6(27)$ & $8(36)$ & \\
\hline Low intensity, $60-150 \mathrm{~min} /$ week & $5(9)$ & $2(9)$ & $2(9)$ & \\
\hline Low intensity, >150 min/week & $16(30)$ & $7(32)$ & $7(32)$ & \\
\hline High intensity, $60-150 \mathrm{~min} /$ week & $2(4)$ & $1(5)$ & $1(5)$ & \\
\hline High intensity, > $150 \mathrm{~min} /$ week & $10(19)$ & $6(27)$ & $4(18)$ & \\
\hline KPS score, mean (SD) & $94(9)$ & $94(10)$ & $94(8)$ & 0.913 \\
\hline
\end{tabular}

Data are presented as $n$ (\%), mean \pm SD and/or median (range). All routine blood tests are presented as median (range); KPS: Karnofsky performance status.

a In only those patients without paid labour productivity at baseline $(n=29)$.

b $P$-value applies to differences between the "on demand"' and preventive groups. 

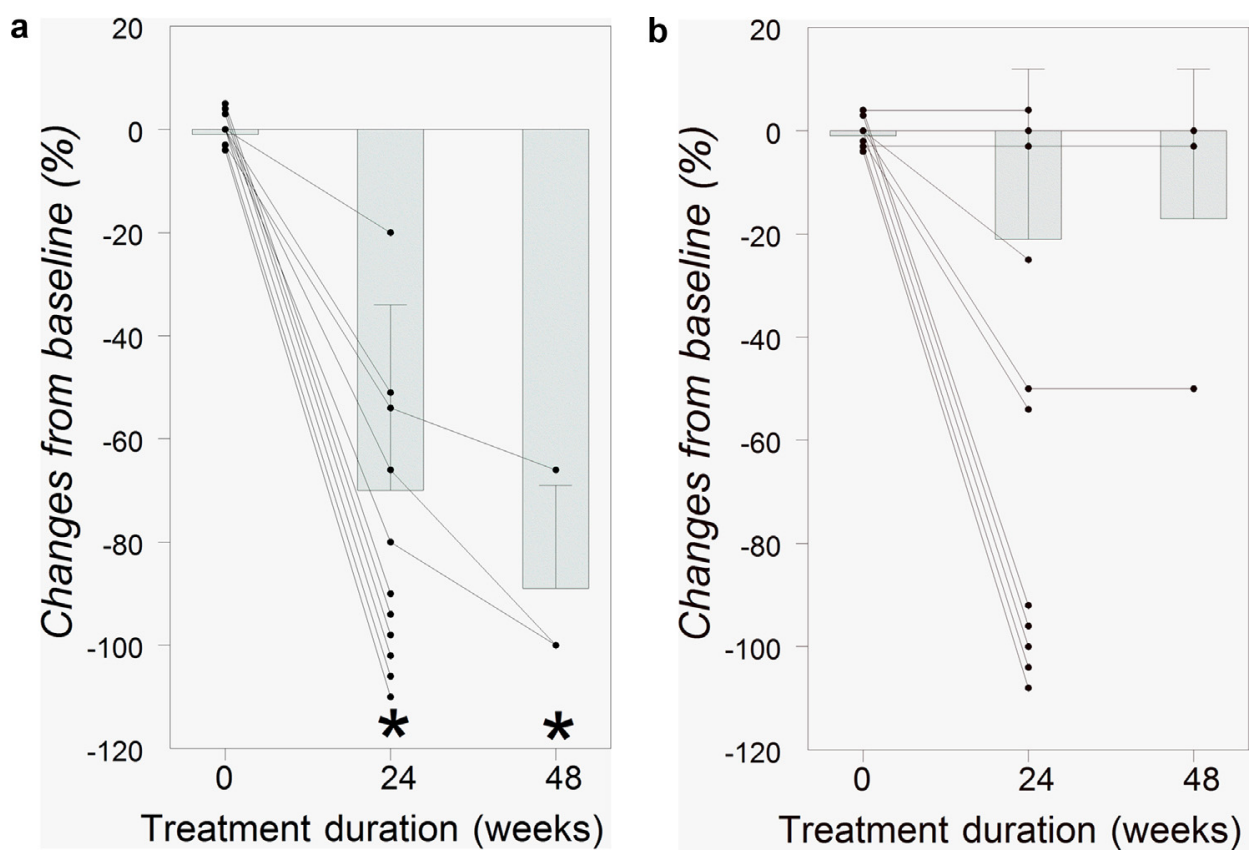

Figure 1 Paid labour productivity as percentage of baseline in patients with chronic hepatitis C with "on demand" nutritional support (a) or preventive nutritional support (b) at 24 and (if applicable) 48 weeks of antiviral treatment ( $n=11$ in both groups, only patients with any paid labour activity at baseline included). Preventive nutritional support significantly decreases loss of paid labour activity. "Indicates significant decrease from baseline in the same group. Dots indicate individual patients connected with lines, bars indicate means with standard deviations. For clarity, some individual points at baseline are depicted slightly above or below zero and error bars positioned upward.

into account regardless of paid labour productivity at baseline, mean paid labour productivity changed with $-35 \%$ vs. $-6 \%$ after 24 weeks of treatment $(P=0.018)$ and with $-8 \%$ vs. $0 \%$ after 48 weeks of treatment in the "on demand" and preventive groups, respectively $(P=0.079)$.

Of the six patients with only unpaid household activities at baseline in the "on demand" group, only one continued performing unpaid household activities during the first 24 weeks of treatment. After 48 weeks, all three patients in the "on demand" group stopped performing unpaid household activities. In contrast, in the preventive group, two of the three patients with only unpaid household activities at baseline continued performing unpaid household activities and the third patient even had started full time white collar paid labour during the first 24 weeks of treatment. After 48 weeks two of these patients still performed part time white collar labour or unpaid household activities, respectively.

\section{Effects of preventive nutritional support during antiviral treatment on physical exercise}

At baseline, many patients (38\%) performed no physical exercise at all, 9\% had 60 to 150 minutes of low intensity exercise per week, $30 \%$ had $>150$ minutes of low intensity exercise per week, $4 \%$ had 60 to 150 minutes of high intensity exercise per week and $19 \%$ had $>150$ minutes of high intensity exercise per week (Table 1 ). In patients who received at least 24 weeks of treatment no significant differences in baseline physical exercise activity were found between the "on demand"' and preventive groups (Table 1). Degree of physical exercise decreased after 24 and 48 weeks of treatment in both groups. Nevertheless, in the preventive group, this reduction was significantly smaller than in the "on demand" group. At 24 weeks of antiviral therapy, physical exercise had decreased with $87 \%$ in the "on demand" group and with $43 \%$ in the preventive group $(P=0.005)$ (Fig. $2 \mathrm{~A}$ and $B)$. In the subgroup of patients with 48 weeks of therapy, decrease of physical exercise at 48 weeks was $90 \%$ in the "on demand" group and $0 \%$ in the preventive group $(P=0.027)$ (Fig. 2A and 2B). These decreases were calculated based on only those patients with any physical exercise activity at baseline $(n=30)$. When the total group $(n=44)$ was taken into account regardless of physical activity at baseline, physical exercise was decreased with $64 \%$ and $25 \%$ at 24 weeks of treatment $(P=0.001)$ and with $64 \%$ and $9 \%$ at 48 weeks of treatment $(P=0.090)$ in the "on demand" and preventive groups, respectively.

\section{Effects of preventive nutritional support during antiviral treatment on performance status}

At baseline, there were no significant differences in performance status between patients in those "on demand" and preventive groups who received at least 24 weeks of treatment. Mean KPS score was $94 \pm 10$ in the "on demand" group and $94 \pm 8$ in the preventive group, indicating that most patients were able to carry out normal activity with only minor symptoms of disease (Table 1). After 24 weeks of treatment, performance status decreased in both groups, but this decrease was significantly higher in the "on demand group"' $(-24 \%)$ than in the preventive group 

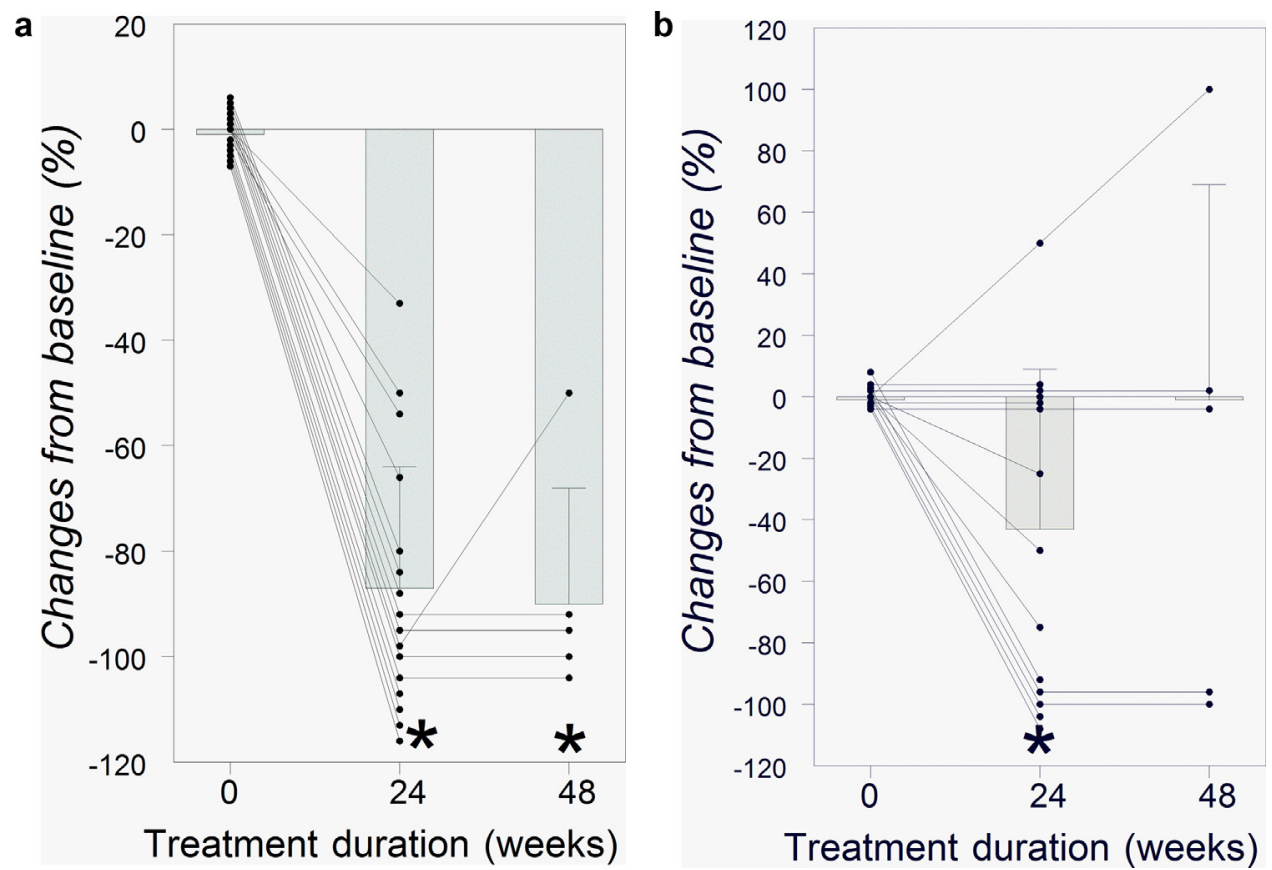

Figure 2 Physical exercise as percentage of baseline in patients with chronic hepatitis C with "on demand" nutritional support (a) or preventive nutritional support (b) at 24 and (if applicable) 48 weeks of antiviral treatment ( $n=16$ and 14 "on demand" and preventive groups, only patients with any physical activity at baseline included). Preventive nutritional support significantly decreases loss of physical activity. "Indicates significant decrease from baseline in the same group. Dots indicate individual patients connected with lines, bars indicate means with standard deviations. For clarity, some individual points at baseline are depicted slightly above or below zero and error bars positioned upward.

$(-12 \%)(P<0.001)$. Similar results were found after 48 weeks of treatment (decrease of $28 \%$ in the "on demand" group and of $15 \%$ in the preventive group, $P=0.017$ ).

\section{Discussion}

Presence of $\mathrm{CHC}$ is associated with significant impact on paid labour productivity, physical exercise and performance status with further deterioration during PEG-interferoncontaining therapy, as underscored in the current work. A major finding of our study is that preventive nutritional advice plus supplementation decreases such loss of paid labour productivity, physical exercise activity and performance status during antiviral therapy for $\mathrm{CHC}$. Interestingly, another study previously reported that acetyl-L-carnitine supplementation during PEG-interferon-containing anti-CHC therapy decreases fatigue and increases quality of life [24]. Recently, it was suggested that acetyl-L-carnitine supplementation also reduces loss of work productivity during anti-CHC therapy [25].

Several studies have investigated the impact of $\mathrm{CHC}$ infection on work impairment in a large number of participants $[15,19,26-30]$. Similar to our findings, proportion of $\mathrm{CHC}$ patients being unemployed in absence of antiviral therapy was high in these studies (range: 7-74\%). Furthermore, CHC-infected workers reported higher levels of overall work impairment than controls [15,19,26-30]. Other studies evaluated the effect of anti-CHC therapy on work impairment. In line with our results, work productivity decreased strongly in patients receiving interferon-containing antiviral therapy.
During anti-CHC treatment, patients reported more absence days and lower productivity compared to baseline or untreated $\mathrm{CHC}$ patients [15-17,31,32]. For example, Aggarwal et al. reported a mean increase in number of absence days of 3 days compared to baseline during the previous month after 12 weeks of anti-CHC therapy. Furthermore more than $50 \%$ of patients reported decreased productivity [17]. Brook et al. [16] reported lower numbers: CHCemployees who received antiviral treatment had 0.52 more health-related work absence days than non-treated $\mathrm{CHC}$ employees, missing an average of 1.27 workdays monthly. Furthermore, treated $\mathrm{CHC}$ employees had $12 \%$ fewer units processed per hour worked than those without treatment, but this difference was not statistically significant [16]. On the other hand, reaching SVR resulted in improvement of paid labour productivity with less absenteeism than in nonresponders [15,31,33]. Previous studies also demonstrated that $\mathrm{CHC}$-patients in general perform less physical exercise than non-CHC subjects $[28,30]$. In our study, proportion of patients who performed no physical exercise at baseline was $38 \%$. During antiviral therapy, physical exercise and Karnofsky performance status decreased strongly in patients without preventive nutritional support. These findings are in line with other studies reporting a decrease in the physical component score of the SF-36 quality of life questionnaire during interferon-containing treatment for CHC [31,32].

In general, productivity is defined as an overall measure of the ratio of the volume of output to the volume of inputs (i.e. units of work processed per hour). Measurement of labour input can therefore be seen as a rough estimation of labour productivity. The true productivity depends on 
multiple factors [34]. Moreover, similar to the current study, most studies regarding impact of $\mathrm{CHC}$ infection and antiviral therapy on work impairment used patient reported instead of objective measures, which may introduce measurement error and bias [15].

Results of the current study were validated in a retrospective group of $111 \mathrm{CHC}$ patients under care in our hospital in the period 2011-2014. In line with findings of the current study, only half of patients performed paid labour at baseline. Furthermore, there was also a strong decrease in paid labour productivity after 24 and 48 weeks of PEG-interferoncontaining antiviral therapy ( $-51 \%$ and $-57 \%$, respectively). Most patients in this group performed physical exercise at baseline. However, there was a dramatic decrease in physical exercise: proportion of patients without any physical exercise increased from $14 \%$ at baseline to $54 \%$ and $77 \%$ after 24 and 48 weeks of treatment, respectively. Although percentages slightly differ between this group and the current study, decreases in paid labour productivity and physical exercise during antiviral therapy are large.

The potential underlying mechanisms for the beneficial effects of nutritional support during antiviral therapy on paid labour productivity, physical exercise and performance status may be an improved nutritional state and higher quality of life, as demonstrated previously [7]. In the "on demand" group of our RCT, there was a trend towards a higher loss of paid labour productivity after 24 weeks of treatment in those patients who performed blue collar labour at baseline than in those with white collar labour (data not shown).

Preventive nutritional support during antiviral therapy and its beneficial effect on paid labour productivity may theoretically be cost-effective. According to the current study, nutritional advice and supplementation during antiviral treatment may reduce costs due to loss of paid labour productivity with $49 \%$. Based on an average income of 28,400 euro in 2010 in The Netherlands (data from Central Bureau of Statistics), nutritional advice and support would lead to a reduction in costs due to loss of paid labour productivity of 6436 euro per patient per 24 weeks of treatment. On the other hand, in the Netherlands total costs for preventive nutritional advice plus evening supplementation during 24 weeks of antiviral therapy are only approximately 660 euro per patient.

Paid labour status is influenced by multiple factors, such as patient preference, co-morbidity and age. Indeed, patients with $\mathrm{CHC}$ may have several comorbidities that limit ability to work. For example, IV drug use is a common mode of transmission of $\mathrm{CHC}$ and is associated with psychiatric conditions [35]. Furthermore, in the current study, two patients had haemophilia and these patients may be restricted by joint problems to perform blue collar labour. Only one patient in the "on demand" group and none in the preventive group was $\geq 65$ years of age and did not have paid labour at baseline.

Recently, several new generation direct-acting antivirals (DAAs) have been approved. Therefore, interferon-free treatment strategies for $\mathrm{CHC}$ are nowadays possible, which are more effective and better tolerated [36-39]. As a result, the role of interferon-containing therapy in $\mathrm{CHC}$ treatment will be limited in the future. However, in specific geographical regions, such as developing countries and other economically deprived regions, interferon-containing antiviral therapy may still be a reasonable option due to excessive costs of the new DAAs [39]. Furthermore, results of the new treatment regimens in genotype 3 -infected patients have been suboptimal [40].

According to a recent publication [41], work productivity may be less affected by dual therapy with sofosbuvir and ribavirin than with triple therapy with sofosbuvir, ribavirin and PEG-interferon. Nevertheless, proportion of patients with paid labour did not decrease during treatment in either group. Impairment in work productivity disappeared within 12 weeks after end of treatment, but recovery took longer in patients who received interferon-containing therapy [41]. Based on analyses of four phase 3 clinical trials of sofosbuvir, the new interferon-free treatment regimens lead to only a minor decrease in health-related quality of life, including the physical component score [42].

Our study has several strengths and limitations. Most important, this study revealed the significant impact of preventive nutritional advice and support on paid labour productivity, physical exercise activity and performance status during PEG-interferon-containing antiviral therapy for $\mathrm{CHC}$, which was not well appreciated in the past. Data was prospectively collected and patients were randomly assigned to the preventive vs. "on demand" groups. On the other hand, as mentioned above, data on paid labour status, physical exercise and performance status relied on patientreported measures. Finally, dietary advice combined with dietary supplementation is more effective in enhancing short-term weight gain and in preventing deterioration of the nutritional status than dietary advice alone [43]. Since our preventive group received both, it cannot be concluded from our data, which component was responsible for the beneficial effects.

In conclusion, preventive nutritional advice and support decreases loss of paid labour productivity, physical exercise and performance status during PEG-interferon-containing treatment for $\mathrm{CHC}$.

\section{Disclosure of interest}

On behalf of all authors, I declare that we have the following potential conflicts of interest:

EJH, SvM, PDS, CMJvN: declare that they have no conflicts of interest concerning this article.

$\mathrm{BvH}$ : advisory board of Abbvie, Bristol-Myers Squibb, Janssen.

HvS: advisory board Bristol-Myers Squibb, Gilead, Abbvie, Janssen, Merck Sharp and Dohme.

JEA: Advisory board Janssen, Merck Sharp and Dohme, Abbvie, ViiV, Bristol-Myers Squibb, Gilead: Speakers Bureau Gilead.

KJvE.: advisory board of Bristol-Myers Squibb, Gilead, Abbvie.

\section{Acknowledgements/financial support}

The original study on effects of preventive nutritional support (performed in 2008-2010) was supported by an unrestricted grant of Merck Sharp and Dohme (MSD, 
Haarlem, the Netherlands). MSD had no influence on any aspect of the study.

\section{References}

[1] Fried MW, Shiffman ML, Reddy KR, Smith C, Marinos G, Goncales Jr FL, et al. Peginterferon alfa-2a plus ribavirin for chronic hepatitis C virus infection. N Engl J Med 2002;347: 975-82.

[2] Khuroo MS, Khuroo MS, Dahab ST. Meta-analysis: a randomized trial of peginterferon plus ribavirin for the initial treatment of chronic hepatitis C genotype 4. Aliment Pharmacol Ther 2004;20:931-8.

[3] Manns MP, McHutchison JG, Gordon SC, Rustgi VK, Shiffman $M$, Reindollar $R$, et al. Peginterferon alfa- $2 b$ plus ribavirin compared with interferon alfa-2b plus ribavirin for initial treatment of chronic hepatitis C: a randomised trial. Lancet 2001;358:958-65.

[4] Zeuzem S, Hultcrantz R, Bourliere M, Goeser T, Marcellin P, Sanchez-Tapias J, et al. Peginterferon alfa-2b plus ribavirin for treatment of chronic hepatitis $\mathrm{C}$ in previously untreated patients infected with HCV genotypes 2 or 3 . J Hepatol 2004;40:993-9.

[5] Seyam MS, Freshwater DA, O’Donnell K, Mutimer DJ. Weight loss during pegylated interferon and ribavirin treatment of chronic hepatitis C. J Viral Hepat 2005;12:531-5.

[6] Nishiguchi S, Shiomi S, Kurooka H, Iwata Y, Sasaki N, Tamori A, et al. Randomized trial assessing gastric emptying in patients with chronic hepatitis $C$ during interferon-alpha or -beta therapy and effect of cisapride. Dig Dis Sci 2002;47:73-8.

[7] Huisman EJ, van HB, van SH, van Nieuwkerk KM, Arends JE, Siersema PD, et al. Preventive versus "on-demand" nutritional support during antiviral treatment for hepatitis C: a randomized controlled trial. J Hepatol 2012;57:1069-75.

[8] Chung RT, Poordad FF, Hassanein T, Zhou X, Lentz E, Prabhakar A, et al. Association of host pharmacodynamic effects with virologic response to pegylated interferon alfa-2a/ribavirin in chronic hepatitis C. Hepatology 2010;52:1906-14.

[9] Nomura H, Miyagi $Y$, Tanimoto H, Kawano A, Yamashita N. Weight loss during telaprevir-based triple therapy due to telaprevir-induced appetite loss. Intern Med 2014;53: 2567-73.

[10] Huisman EJ, Trip EJ, Siersema PD, van HB, van Erpecum KJ. Protein energy malnutrition predicts complications in liver cirrhosis. Eur J Gastroenterol Hepatol 2011;23:982-9.

[11] Plank LD, Gane EJ, Peng S, Muthu C, Mathur S, Gillanders L, et al. Nocturnal nutritional supplementation improves total body protein status of patients with liver cirrhosis: a randomized 12-month trial. Hepatology 2008;48:557-66.

[12] Alvares-da-Silva MR, Reverbel da ST. Comparison between handgrip strength, subjective global assessment, and prognostic nutritional index in assessing malnutrition and predicting clinical outcome in cirrhotic outpatients. Nutrition 2005;21:113-7.

[13] Mathiowetz V, Weber K, Volland G, Kashman N. Reliability and validity of grip and pinch strength evaluations. J Hand Surg Am 1984;9:222-6.

[14] Webb AR, Newman LA, Taylor M, Keogh JB. Hand grip dynamometry as a predictor of postoperative complications reappraisal using age standardized grip strengths. JPEN J Parenter Enteral Nutr 1989;13:30-3.

[15] Manne V, Sassi K, Allen R, Saab S. Hepatitis C and work impairment: a review of current literature. J Clin Gastroenterol 2014;48:595-9.

[16] Brook RA, Kleinman NL, Su J, Corey-Lisle PK, Iloeje UH. Absenteeism and productivity among employees being treated for hepatitis C. Am J Manag Care 2011;17:657-64.
[17] Aggarwal J, Vera-Llonch M, Donepudi M, Suthoff E, Younossi Z, Goss TF. Work productivity among treatment-naive patients with genotype 1 chronic hepatitis $C$ infection receiving telaprevir combination treatment. J Viral Hepat 2015;22:8-17.

[18] Dibonaventura MD, Yuan Y, Lescrauwaet B, L'italien G, Liu GG, Kamae I, et al. Multicountry burden of chronic hepatitis $C$ viral infection among those aware of their diagnosis: a patient survey. PLoS One 2014;9:e86070.

[19] Dibonaventura MD, Wagner JS, Yuan Y, L'italien G, Langley $P$, Ray KW. The impact of hepatitis $C$ on labor force participation, absenteeism, presenteeism and non-work activities. $\mathrm{J}$ Med Econ 2011;14:253-61.

[20] Ghany MG, Strader DB, Thomas DL, Seeff LB. Diagnosis, management, and treatment of hepatitis C: an update. Hepatology 2009;49:1335-74.

[21] European Association for the Study of the Liver. EASL Clinical Practice Guidelines: management of hepatitis $C$ virus infection. J Hepatol 2011;55:245-64.

[22] Ghany MG, Nelson DR, Strader DB, Thomas DL, Seeff LB. An update on treatment of genotype 1 chronic hepatitis $C$ virus infection: 2011 practice guideline by the American Association for the Study of Liver Diseases. Hepatology 2011;54:1433-44.

[23] Karnofsky DA, Burchenal JH. The clinical evaluation of chemotherapeutic agents in cancer. In: MacLeod CM, editor. Evaluation of chemotherapeutic agents. New York: Columbia University Press; 1949. p. 191-205.

[24] Malaguarnera M, Vacante M, Bertino G, Neri S, Malaguarnera M, Gargante MP, et al. The supplementation of acetyl-L-carnitine decreases fatigue and increases quality of life in patients with hepatitis $C$ treated with pegylated interferon-alpha $2 \mathrm{~b}$ plus ribavirin. J Interferon Cytokine Res 2011;31:653-9.

[25] Malaguarnera G, Pennisi M, Gagliano C, Vacante M, Malaguarnera $M$, Salomone S, et al. Acetyl-L-carnitine supplementation during HCV therapy with pegylated interferon-alpha 2b plus ribavirin: effect on work performance; a randomized clinical trial. Hepat Mon 2014;14:e11608.

[26] Su J, Brook RA, Kleinman NL, Corey-Lisle P. The impact of hepatitis $C$ virus infection on work absence, productivity, and healthcare benefit costs. Hepatology 2010;52:436-42.

[27] Liu GG, Dibonaventura MD, Yuan Y, Wagner JS, L'Italien GJ, Langley $P$, et al. The burden of illness for patients with viral hepatitis C: evidence from a national survey in Japan. Value Health 2012;15:S65-71.

[28] El Khoury AC, Vietri J, Prajapati G. The burden of untreated hepatitis C virus infection: a US patients' perspective. Dig Dis Sci 2012;57:2995-3003.

[29] Dibonaventura MD, Yuan Y, Wagner JS, L'Italien GJ, Lescrauwaet B, Langley P. The burden of viral hepatitis C in Europe: a propensity analysis of patient outcomess. Eur J Gastroenterol Hepatol 2012;24:869-77.

[30] Vietri J, Prajapati G, El Khoury AC. The burden of hepatitis C in Europe from the patients' perspective: a survey in 5 countries. BMC Gastroenterol 2013;13:13-6.

[31] McHutchison JG, Ware Jr JE, Bayliss MS, Pianko S, Albrecht JK, Cort $\mathrm{S}$, et al. The effects of interferon alpha-2b in combination with ribavirin on health related quality of life and work productivity. J Hepatol 2001;34:140-7.

[32] Perrillo R, Rothstein KD, Rubin R, Alam I, Imperial J, Harb $\mathrm{G}$, et al. Comparison of quality of life, work productivity and medical resource utilization of peginterferon alpha $2 a$ vs the combination of interferon alpha $2 \mathrm{~b}$ plus ribavirin as initial treatment in patients with chronic hepatitis C. J Viral Hepat 2004;11:157-65.

[33] John-Baptiste AA, Tomlinson G, Hsu PC, Krajden M, Heathcote EJ, Laporte A, et al. Sustained responders have better quality of life and productivity compared with treatment failures long after antiviral therapy for hepatitis C. Am J Gastroenterol 2009; 104:2439-48. 
[34] Phelps MG. UK Centre for the measurement of government activity. Comparing the different estimates of productivity produced by the office national statistics; 2010.

[35] El-Serag HB, Kunik M, Richardson P, Rabeneck L. Psychiatric disorders among veterans with hepatitis $C$ infection. Gastroenterology 2002;123:476-82.

[36] American Association for the Study of Liver Diseases, Infectious Diseases Society of America. Recommendations for Testing, Managing and Treating Hepatitis C; 2014. Retrieved from http://hcvguidelines.org/

[37] Muir AJ. The rapid evolution of treatment strategies for hepatitis C. Am J Gastroenterol 2014;109:628-35.

[38] European Association for the Study of the Liver. EASL recommendations on treatment of hepatitis C. J Hepatol 2015 [Epub ahead of print].
[39] Gane E. Hepatitis C beware-the end is nigh. Lancet 2014;384:1557-60.

[40] Pol S, Vallet-Pichard A, Corouge M. Treatment of hepatitis C virus genotype 3-infection. Liver Int 2014;34:18-23.

[41] Younossi ZM, Stepanova M, Henry L, Gane E, Jacobson IM, Lawitz E, et al. Effects of sofosbuvir-based treatment, with and without interferon, on outcome and productivity of patients with chronic hepatitis C. Clin Gastroenterol Hepatol 2014;12:1349-59.

[42] Younossi ZM, Stepanova M, Henry L, Gane E, Jacobson IM, Lawitz $\mathrm{E}$, et al. Minimal impact of sofosbuvir and ribavirin on health related quality of life in chronic hepatitis $\mathrm{C}(\mathrm{CH}-\mathrm{C})$. J Hepatol 2014;60:741-7.

[43] Baldwin C, Weekes CE. Dietary advice for illness-related malnutrition in adults. Cochrane Database Syst Rev 2007;1:CD002008. 